\title{
EMERY-DREIFUSS MUSCULAR DYSTROPHY
}

\author{
ANATOMICAL-CLINICAL CORRELATION
}

CASE REPORT

\author{
ALZIRA ALVES DE SIQUEIRA CARVALHO*, J OSÉ ANTONIO LEVY**, \\ PAULO S. GUTIERREZ***, SUELY KAZUE NAGAHASHI MARIE*, \\ EDUARDO ARGENTINO SOSA****, MAURÍCIO SCANAVACA****
}

\begin{abstract}
We report on a man that had weakness of humeroperoneal distribution associated with limited range of motion of the cervical spine and elbows since he was 5 years old . At age 26 he developed tachycardia episodes. A complex arrhythmia was discovered, and a nodal ablation was done with a cardiac pacemaker implanted. The patient had an arrhythmia and sudden death followed this. Emery-Dreifuss muscular dystrophy is a rare recessive $\mathrm{X}$-linked muscular disorder where mixed patterns in electromyography and muscle histology (neurogenic and/or myopathic) have caused nosological confusion. The autopsy findings are here described and correlated to the clinical features in an attempt to better understand the ambiguous findings concerning the process etiology .
\end{abstract}

KEY WORDS: muscular dystrophy, arrhythmia, muscle, biopsy.

\section{Distrofia muscular de Emery-Dreifuss: correlação anátomo-clínica (relato de caso)}

RESUMO - Relatamos o caso de um paciente com fraqueza muscular de distribuição úmero-peroneal associada a limitação de movimentos da coluna cervical e cotovelos. Aos 26 anos, ele desenvolveu episódios de taquicardia. Uma arritmia complexa foi descoberta sendo feito ablação nodal seguida por implante de marcapasso cardíaco. O paciente evoluiu com arritmia e morte. A distrofia de Emery-Dreifuss é desordem muscular rara, recessiva, ligada ao cromossomo X cujo aspectos mistos (neurogênico e/ou miopático) na eletroneuromiografia e biopsia muscular tem provocado dúvidas na nosologia. Os achados de autopsia são descritos e correlacionados aos critérios clínicos na tentativa de melhor compreender os achados ambíguos em relação à etiologia.

PALAVRAS-CHAVE: distrofia muscular, arritmia, músculo, biopsia.

Emery-Dreifuss muscular dystrophy (EDMD) is a rare disease characterized by early contractures (especially in the neck, elbows and ankles), slowly progressing muscle weakness more prominent in humeroperoneal region, onset between 5 and 15 years of age, and peculiar cardiac problems followed by death in some cases and need for a permanent cardiac pacemaker in others ${ }^{1-5}$. The first report of this syndrome was compatible with an X-linked recessive myopathy. In 1985, it was published the first report of two related females in whom the inheritance seemed to be autosomal dominant ${ }^{2}$.

We report on a case of EDMD.

Setor de Doenças Neuromusculares do Departamento de Neurologia da Faculdade de Medicina da Universidade de São Paulo (FMUSP) . * Neurologist; **Associate Professor of Neurology; ***Pathologist of the INCOR (Instituto do Coração / FMUSP) ; ****Cardiologist of the INCOR Aceite: 23-agosto-2000. 


\section{CASE}

The patient was 1 of 3 brothers. He was 1 of 2 affected, and there was no family history of consanguinity or other diseases, nor any known instances of sudden death. The patient's brother had the same problem but , he was not seen because he denied to be submitted to exams. The birth and early development of our patient were normal. At age 5, deformities characterized by elbow, knee and ankle contractures, as well, cervical rigidity were noticed.At age 7, he noticed that he could not straighten his elbows and later he recalled that he had never been able to run fast or jump. He was intelligent. At the time, the diagnosis was of spinal muscular atrophy. The patient was seen for the first time in our hospital when he was 26, presenting cardiac arrhythmia and episodes of sight darkening. From that date on he was a patient at a specialized cardiac arrhythmia center in another town where myocardiopathy associated to ventricular arrhythmia was diagnosed. Two years later however, he presented ventricular tachycardia requiring hospital internment.

As he developed monomorphic ventricular tachycardia, ablation with radiofrequency was attempted two times with no success. Electrophysiological mapping showed ventricular tachycardia originating in the right ventricle septum. Hence, a pacemaker placement was suggested. Cardiologic evaluation performed at our heart Institute (INCOR) showed significant depression of left ventricle function associated with complex arrhythmia as sinus arrest (episodes with escape junctional rhythm resulting in bradycardias at rates of 35 beats $/ \mathrm{min}$ ) with unspecific atrioventricular (AV) conduction and intraventricular disturbances (intermittent first degree AV block) associated with frequent and repetitive atrial ectopic and ventricular activity . Considering all these alterations we suggested total atrioventricular block induction by ablation of atrioventricular knots followed by pacemaker implantation.

The neurological examination showed general amyotrophy and weakness against slight resistance of deltoids, biceps, and triceps, with good strength of hand muscles. Active and passive motion at the hips was normal. Leg muscles were strong except for slight weakness of the anterior tibials and peroneals. He could walk on his toes but not on his heels. The patient's neck could not be flexed actively. Cranial muscles were normal. Reflexes were not elicited in the arms, knee and ankle. There were no fasciculations .

Routine laboratory studies were normal except serum creatine kinase activity that was 276 UI (normal 1 - 50) . Electroneuromyogram (ENMG) and muscle biopsy were carried out concurrently. ENMG findings showed fibrillations and fasciculations. Motor units seemed prolonged in duration, very polyphasic, increased in amplitude and moderately reduced in numbers in all muscles tested. The motor nerve conduction velocities and sensory latencies were normal. These changes were indicative of a neurogenic disorder. Muscular biopsy of a deltoid muscle showed increased variability in muscle fiber size due to moderate numbers of atrophic and hypertrophic muscle fibers. The endomysial connective tissue was increased. Fiber splitting and scattered fibers with basophilic sarcoplasm and large pale nuclei with prominent nucleoli were seen. Enzyme histochemistry studies revealed a clear distinction of fiber types (Fig 1). No type grouping or angular fibers were seen. About $75 \%$ of the fibers were type II. No specific abnormalities of mitochondria, lipid or polysaccharide were seen in Gomori trichrome, oil red O, or periodic acid-Schiff stains (Fig 1). Immunocytochemical staining for dystrophin showed normal distribution to the sarcolemma.

One day after successful ablation of atriventricular knots induction, the patient underwent third generation pacemaker placement under general anesthesia. In the first night prior to implantation the patient developed a ventricular tachycardia reverted by electrical shock. However, that was followed by irrecoverable asystole.

Autopsy findings revealed progressive myocardial fibrosis with early and severe atrial involvement. Anatomical-pathological investigation of heart showed focal atrophy and fine bands of fibrosis or fat replacing ventricular and atrial myocardial fibers underlying arrhythmia. There were no abnormalities of the central nervous system or the spinal cord. There were no significant morphological findings in the other organs.

\section{DISCUSSION}

According to Galassi et al. ${ }^{3}$, in 1966, Emery and Dreifuss described a new form of X-linked recessive muscle dystrophy strongly characterized by cardiac abnormalities and absence of calf muscle hipertrophy. In 1979, Rowland et al. ${ }^{1}$ reviewed all cases reported up to that time, and defined a new clinical affection emphasizing 5 cardinal criteria: X-linked recessive inheritance, humeroperoneal muscle weakness, early involvement of lower limbs distal muscles, slow evolution and cardiac abnormalities.

Criteria to establish diagnosis of EDMD have been recently postulated ${ }^{2}$ :(1) early contractures of Achilles heel, elbows and spine; (2) slow progression of muscular atrophy and bilateral symmetric 


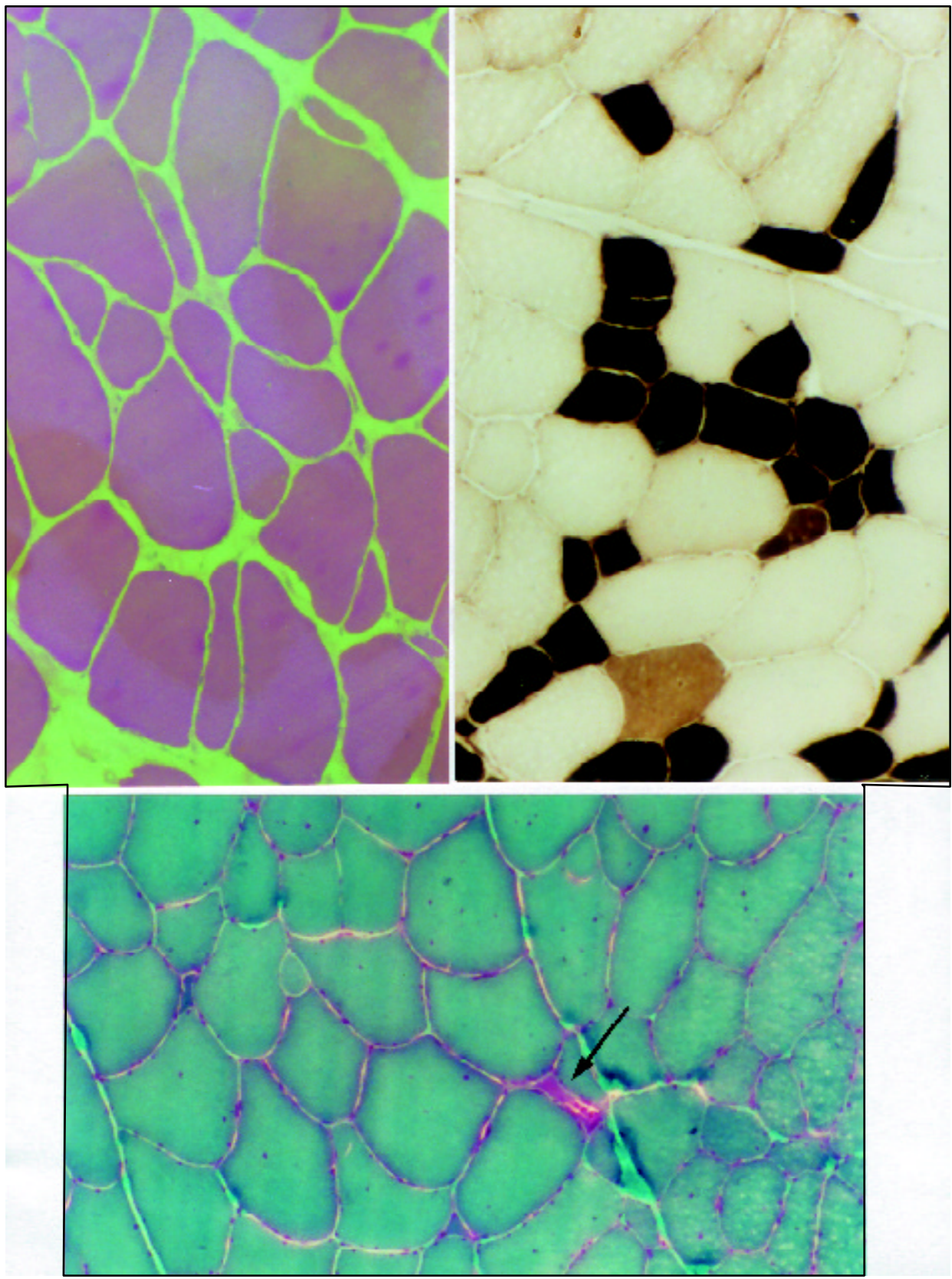

Fig 1. Left: $H \& E$ stain of the brachial biceps biopsy obtained from the patient, showing variation in fiber size, internally located nuclei, fiber splitting, increased endomysial connective tissue. Right: myosin ATPase, pH 4.3, showing enzyme histochemistry of the same muscle. Most of fibers type IIA are hypertrophic, atrophy involving type I fibers that occasionally occur in small groups. Most of fibers are type II. Below: Gomori trichrome showing no "ragged red fibers" and a necrotic muscle fiber (arrow) and several muscle fibers internally placed nuclei. 
weakness prominent in humeroperoneal muscle; (3) abnormality of cardiac conduction and/or another cardiomyopathy evidence; (4) muscular biopsy revealing myopathic aspects or muscle dystrophy; (5) pedigree consistent with X-linked inheritance. Cases reported have been described under a variety of names, including scapuloperoneal syndrome, X-linked muscular dystrophy with contractures, rigid spine syndrome, Cestan- Lejonne syndrome and humeroperoneal neuromuscular disease ${ }^{1}$.

The patient in this report presented with the following clinical characteristics: early muscular contractures, especially of the cervical muscles, elbows and ankles; cardiac arrhythmia; mild muscular weakness; myopathic muscular biopsy and electromyogram revealing neurogenic pattern.

Muscle weakness distribution in EDMD is commonly humeroperoneal, as in the case of our patient. However, scapulopelvic and humeropelvic distributions have also been reported ${ }^{3}$. As for cardiac conduction disturbances, the most common arrhythmias are first degree atrioventricular (AV) block and complete heart block. Other abnormalities have also been described such as : paroxysmal atrial tachycardia, atrial fibrillation, atrial flutter, branch block, second degree AV block and ventricular tachycardia ${ }^{4}$. Cardiac symptoms appear between the third and fifth decades of life and may result in sudden death ${ }^{5,6}$. Syncopal episodes, as in the case of our patient, had their onset at age 24, with no other symptoms reported until then. Dickey et al.(apud Bialer et al. ${ }^{5}$ ), were the first to emphasize that female carriers are at substantial cardiac risk. Continued careful cardiologic followup of family is required so as to detect carriers, and as a preventive measure ${ }^{6}$.

It is important to point out that cardiac problems in EDMD are distinctive from those in Duchenne (DMD) and Becker (BMD) muscular dystrophy. ECG alterations in DMD and BMD patients may reveal right-sided predominance and sinus arrhythmias, but rarely AV nodal block ${ }^{4,5}$. The limb girdle muscular dystrophy rarely has similar presentation ${ }^{4,5,7}$.

Neurological characteristics defined by muscular weakness and amyotrophy associated with severe cardiac arrhythmia make us think of this as a case of EDMD. However, further investigations may provide us with a different diagnosis.

Spinal muscular atrophy is a disturbance characterized by genetic heterogeneity which may be autosomal recessive, autosomal dominant and X-linked recessive inheritance, or of sporadic form. This affection of the anterior horn cells and of the motor nuclei of some cranial nerves, may present with cardiac abnormalities, in some cases, but not with atriventricular block. The arrhythmogenic ventricular dysplasia, whose etiology has not yet been established and is more rare than EDMD, may appear as an atrial arrhythmia similar to EDMD, but there is no neurologic commitment ${ }^{10}$. Myotonic dystrophy and facioscapulohumeral muscular dystrophy should also be mentioned here, as they may sometimes feature atrial arrhythmias as the ones in EDMD.

In EDMD, muscular biopsy was compatible with dystrophic myopathy, but the electromyogram can show mixed neurogenic and/or myopathic patterns for some unknown reason, as Rowland had suggested. In several families and sporadic cases mentioned in literature, the patterns in EMG or muscle biopsy or both were compatible with myopathy ${ }^{1}$ In several descriptions of the EMG, however, the ambiguities with EMG signs of denervation and myophatic patterns have been mentioned ${ }^{1,11}$. Even though our patient had featured myopathic alterations in the skeletal muscles, the electromyogram showed a neurogenic pattern. Spinal cord and brain studies did not reveal morphological alterations.Autopsy findings in literature also show this ${ }^{1}$.

The gene for EDMD has recently been mapped to $\mathrm{Xq} 28^{8,12}$ long distal arm with clear evidence of genetic heterogeneity in EDMD. A number of families have been reported which fit an autossomal dominant pattern of inheritance. An affected female born of a consanguineous union was classified as autosomal recessive inheritance. Some other sporadic cases, including in women, have been reported $^{2,3,8}$.

Although some authors have suggested the possibility of two distinct genetic disorders leading 
to the same phenotypic expression, Rowland finds it difficult that two entities genetically distinct originate such different symptoms and signals ${ }^{1}$. It should be pointed out, however, that "limb girdle type" progressive muscular dystrophy featured by different genes that have been recently mapped, has the same phenotype ${ }^{13}$. Therefore, it should be very interesting to consider the possibility of the existence of two distinctive genetic disorders, resulting from different electromyographic and biopsy patterns as reported in literature, but giving rise to similar phenotypic expressions. Would it be daring of us to suspect that this same phenomenon takes place in "limb girdle type" dystrophy?

The necropsy alone would not allow us to make a diagnosis. Only the correlation with clinical data, particularly neurological data, led us to suspect an EDMD. However, findings are similar to those cases of this disease described in literature ${ }^{1,6}$ but, in some of them the alterations are more remarkable. On the other hand, the degenerative signs in the myocardium, although discreet, could be correlated with arrhythmia. They are the same type as the ones seen in arrhythmogenic ventricular dysplasia of the right ventricle ${ }^{10}$. The similarity of morphological and electrophysiological patterns between these two entities suggest that, just as in EDMD , myocardical degeneration , possibly congenital, occurs in ventricular dysplasia.

We believe that the patient's clinical diagnosis should be held as priority . Finally, it is worth to point out the importance of patients' clinical diagnosis, as neurological changes almost never rise as an impediment, whereas cardiac affection is potentially lethal ${ }^{5}$. The ENMG and biopsy differences should be attributed to processes we do not understand.

Thus, early disease diagnosis would make it possible for affected individuals to have a longer survival, besides allowing detection of carriers by means of molecular biology techniques and linkage analysis ${ }^{8}$. Although EDMD is not such a disabling disorder physically as the Duchenne and Becker forms, the combination of progressive muscle weakness and, in particular, the serious cardiac complications result in considerable morbidity and at times mortality, so that accurate identification of carrier status and prenatal prediction using closely linked probes ${ }^{8,12}$ should be of help to family members.

\section{REFERENCES}

1. Rowland LP, Fetel M, Olarte M, Hays A, Singh N, Wanat FE. Emery-Dreifuss muscular dystrophy. Ann Neurol 1979;5:111-117.

2. Miller RG, Layzer RB, Mellenthin MA, Golabi M, Francoz RA, Mall JC. Emery-Dreifuss muscular dystrophy with autossomal dominant transmission. Neurology 1985;35:1230-1233.

3. Galassi G. Modena MG, Benassi A, et al. Autosomal-dominant dystrophy with humeroperoneal weakness and cardiopathy: a genetic variant of Emery-Dreifuss disease?. Ital J Neurol Sci 1986;7:125-132.

4. Bethlem J, Knobbout CE.Neuromuscular diseases. In Bethlem J, Knobbout CE (eds). Emery-Dreifuss muscular dystrophy. Oxford: Oxford Medical Publications, 1987;25-64. 5. Bialer MG., Mc Daniel NL, Kelly TE. Progression of cardiac disease in Emery-Dreifuss muscular dystrophy. Clin Cardiol 1991;114:411-416.

6. Fishbein MC, Siegel RJ, Thompson CE, Hopkins LC. Sudden death of a carrier of X-linked Emery-Dreifuss muscular dystrophy. Ann Intern Med 1993;119:900-905.

7. Kawashima S, Ueno M, Kondo K, Yamamoto J, Iwasaki T. Marked cardiac involvement in limb-girdle muscular dystrophy: case report. Am J Med Sci 1990;299:411.

8. Kress W, Muller E, Kausch K, Kullmannn ML. et al . Multipoint linkage mapping of the Emery-Dreifuss muscular dystrophy gene. Neuromusc Disord 1992;2:111-115.

9. Emery EHA. The nosology of the spinal muscular atrophies. J Med Genet 1971;8:481

10. Gerlis LM, Schmidt-Ott CS, Ho Sy, Anderson RH. Dyspastic conditions of the right ventricular myocardium: Uhl's anomaly v. arrhythmogenic right ventricular dysplasia. Br Heart J 1993;69:142-150.

11. Panegyres PK, Mastaglia FL, Kakulas BA. Limb girdle syndromes: clinical, morphological and electrophysiological studies. J Neurol Sci 1990;95:201-218.

12. Thomas NST, Williams H, Elsas LJ, Hopkins LC, Sarfarazi M, Harper PS. Localisation of the gene for Emery-Dreifuss muscular dystrophy to the distal long arm of the X chromosome. J Med Genet 1986;23:596-598.

13. Passos-Bueno MR, Moreira ES, Marie SKN, et al. Relative proportion and main clinical features for the four mapped autossomal recessive limb-girdle muscular dystrophies in 12 Brazilian families. J Med Genet 1995 (accepted) . 